Received November 30, 2018

Revised December 3, 2018

Accepted December 10, 2018

\title{
United Nations Contributions to Promoting Human Rights in the DPRK: Impetus for Change
}

\author{
JINA $\mathrm{CHOI}^{*}$ AND BRENDAN HOWE**
}

\begin{abstract}
The United Nations (UN) has been the key contributor to the diffusion of human rights norms and practices in the Democratic People's Republic of Korea (DPRK). The process of promoting human rights in the DPRK has been beset with challenges. The UN has had to steer its way through a complex web of international politics in order consistently to apply pressure on Pyongyang to amend its human rights norm-violating behavior. While achievements to date have been limited, this paper identifies the processes of socialization rather than coercion or inducements, as constituting the most promising avenue for the UN to impact North Korean governance. The paper will examine the evolution of UN socialization efforts in the DPRK to date, including how and under what mechanisms or conditions, socialization occurred, and what progress has been made by UN socialization dynamics. Although the progress so far may have been limited at best, what has been achieved merits greater scholarly attention, in order to derive implications for future policy prescription with regard to promoting human rights in North Korea and beyond.
\end{abstract}

Keywords: Intergovernmental Organizations (IGOs), United Nations (UN), Human Rights Promotion, Socialization, Norm Diffusion

* First Author, Lecturer, Kyonggi University, South Korea;

E-mail: j.choi3935@gmail.com

** Professor, Ewha Womans University, South Korea;

E-mail: bmg.howe@gmail.com

DOI: 10.16934/isr.19.2.201812.115 


\section{INTRODUCTION}

Since its inception in 1948, the Democratic People's Republic of Korea (DPRK) regime has neglected its duties to protect or guarantee minimal rights for its citizens and has resisted becoming an international norm-abiding state. The sufferings of the majority of its citizens have not been addressed by the regime, and human rights conditions have deteriorated significantly in the face of both endogenous and exogenous crises. Internal and external policy and governance failures have negatively impacted on the daily lives of citizens, making them ever more insecure, as well as denying them the most fundamental human rights. Pyongyang's policy-making has, ultimately, also been counterproductive. A focus on military-first (Songun) during Kim Jong-il era, followed by one half of Kim Jong-un's byungjin policy of parallel development of the economy and nuclear weapons, has meant that state security has deprived the people of resources and rights, which in turn have undermined trust in the government to alleviate the challenges faced by people in their everyday lives. This has led to greater regime insecurity, and therefore a greater emphasis on state security, as well as the deliberate destabilization of the international operating environment in order to create conditions, which justify national security policy prioritization. A vicious circle.

The human rights situation in the DPRK is an ongoing issue of great concern for the international community. The $\mathrm{UN}$ and related agencies have been foremost among Intergovernmental Organizations (IGOs) in addressing the human rights situation in North Korea. Although non-binding, a North Korean Human Rights Resolution has been adopted by the UN General Assembly every consecutive year since 2005 (Baek 2013, 123). On December 19, 2017, the United Nations Third Committee, otherwise known as the Social, Cultural, and Humanitarian Committee, passed the 13th North Korean Human Rights Resolution by consensus (UNGA 2018). As can be inferred from the broad support for the Resolutions, the UN and most of its member states share the common goals of bringing about change in the DPRK, seeking ways in which to ensure accountability for human rights violations, as well as transitioning North Korea towards becoming a norm-abiding state.

The UN and its member states have used a variety of strategies in attempting to change the DPRK's behavior. These can broadly be grouped into those related to coercion, to those offering incentives, and to those related to socialization. The first two policy groupings have not only been broadly unsuccessful, but can, under certain circumstances, even be seen as counter-productive. Thus, it is the third area of engagement that serves as the prime focus for this article. The central research question is, given the failure of coercive and incentivizing approaches, what hope is there for the socializing alternative, based upon what 
logical premises, and which manifestation of socialization mechanisms holds the greatest promise? Given the paucity and unreliability of data on North Korea, this paper takes a qualitative rather than quantitative approach, reliant upon statements from IGO, governmental, and non-governmental sources. It is more concerned, however, with the internal logic and dynamics of the socialization processes, comparing them with each other as well as with coercion and incentivization.

The basic logic of a coercive approach is to induce change in a target state's behavior through impacting their rational cost-benefit analysis, increasing the costs of choosing the undesirable course of action. To date, coercive measures have dominated international engagement with the DPRK. The most common way for the UN to attempt coercion of North Korea has been through imposing political and economic sanctions. The UN has been imposing sanctions against the DPRK, through the UN Security Council (UNSC) since 2006. The first UNSC sanction was Resolution 1718 in the aftermath of North Korea's first nuclear test (UNSC 2006). Yet, the multiple UN sanctions that have been imposed against the DPRK since 2006 have, thus far, failed to bring about positive changes by the DPRK regime. They have been ineffective in targeting the core of regime, as a result of which the DPRK seems to have increased its resilience to UN sanctions. More problematically, there are very high potential adverse impact of sanctions, particularly on the ordinary and the most vulnerable citizens in the DPRK (UNHRC 2018, 4). In addition, the presence of sanctions can be used by Pyongyang to support the narrative of a hostile international operating environment justifying military first and other policies, which sacrifice the rights of the individual in the name of state security.

On the other hand, the basic logic of positive inducements or incentives is that the rational cost-benefit calculations of the target state are influenced in a way that choosing the course of action desired by those attempting the influence becomes more desirable. In the case of the DPRK, positive inducement measures have been taken by a number of concerned stakeholders including the United States (US), the Republic of Korea (ROK), and the UN. Although, elsewhere, such measures have reasonably good operational records in transforming the behavior of rogue regimes (Nincic 2010), they do not seem to have had a similar positive impact upon the DPRK. For the US, the 1994 "Agreed Framework" was the major attempt at engagement with the DPRK, under which it was agreed that North Korea would freeze its nuclear program and allow enhanced International Atomic Energy Agency (IAEA) safeguards in return for replacement of the DPRK's graphite-moderated reactors with light-water (LWR) power plants, supplies of heavy oil, and full normalization of political and economic relations (Howe 2012, 75). Neither side fulfilled their commitments under the Agreement. Furthermore, it was primarily focused on changing Pyongyang's behavior with regard to nuclear proliferation rather than human rights. For South Korea, the 
main avenue of economic engagement was through the Kaesong Industrial Complex (KIC). The KIC became seriously politicized by both sides and has been completely shut down since 2016 (McCurry 2016).

Meanwhile, the UN has engaged directly with the DPRK in an effort to fund humanitarian projects, thereby contributing to human rights. These efforts have, however, for many years, been troubled by chronic underfunding problems. UN humanitarian funding has, in fact, gradually decreased, mainly due to the reluctance of donor nations to continue to contribute (UNHCT 2015). For instance, in years of 2013 and 2014, only 40 percent of the necessary budgets originally requested were eventually provided. In 2015, only 17 percent of funding was forthcoming for humanitarian projects in the DPRK, clearly not enough to help all those in need, particularly when taking into account the natural disasters which beset North Korea at this time (UNHCT 2015, 14). The funding situation has, largely remain unchanged since then. Distrust on both sides, the DPRK government and the international community, hampers the effectiveness of aid and contributes to donor fatigue. Indeed, the giving of any assistance to North Korea is controversial.

Critics point to the diversion of resources intended to alleviate suffering instead to government officials and the military. Furthermore, international aid can be seen as keeping the existing regime afloat by covering some of its governance costs (Howe and Park 2014, 49). The reluctance of donor nations to contribute to UN humanitarian missions in the DPRK have mostly been driven by these political sensitivities, and the gradual decrease in funding will most likely hinder operations to help the most vulnerable citizens in the DPRK. The UN humanitarian team and its related agencies also, however, found that sanctions have hindered the smooth operation of aid and assistance projects in the DPRK. As a result of sanctions, there were delays in operations in 2017 related to difficulties in securing banking channels and clearances (UNHCT 2016; UNHCT 2017, 15; UNHRC 2018, 4).

In addition to the annually-adopted Resolutions by the General Assembly, the UN has, in recent years, attempted a variety of different measures and approaches in dealing with the human rights situation of the DPRK, which can be seen as manifesting a socialization approach. Chief and most successful among these has been "naming and shaming." The UN Third Committee conducted a systematic assessment of the wide range of human rights violations that have been committed by the North Korean regime through a special commission of inquiry (COI) which detailed them in a report in February 2014. The Third Committee took the UN special commissions' February 2014 report to the UN General Assembly (UNGA), and then to the UNSC. In late 2014, The Third Committee requested the UNSC to refer the DPRK regime and its human rights-violating leader, Kim Jong-un, to the International Criminal Court (ICC) to 
face charges of crimes against humanity (A/HRC/25/CRP.1 2014).

In contrast to coercion and incentivization, this paper will demonstrate that socialization approaches have not only succeeded in bringing wider international attention to the plight of vulnerable individuals and groups in the DPRK but have also contributed to bringing about changes (albeit limited) in the target state's behavior. The paper will examine in more detail the UN's attempts at a socialization approach, and also the prospects for further socialization agendas. The next section considers the roles that different forms of socialization can play in transforming the behavior of target states, and the mechanisms through which they are implemented at the UN. This will be followed in section three by a detailed analysis of how the UN has attempted to socialize the DPRK, addressing both achievements, and enduring obstacles.

\section{SOCIALIZATION IN THEORY AND IGO PRACTICE}

Goodman and Jinks have noted the shortcomings of conventional approaches such as coercion and incentivization as being related to a failure to grasp the complexity of the social environment within which states act, and a failure to account for many ways in which social and legal norms diffuse (Goodman and Jinks 2004, 625). International norms in fact influence significantly both domestic and international political decision- and policy-making. English School rationalists have long explained the behavior of states as being a product of socialization through repeated interactions with each other, which throw up common norms and principles to which all are inclined to adhere.

The concept of an international "society" (as best manifested in the UN), the rules and norms of which have a "civilizing" influence upon its members is key to this perspective. For Hedley Bull (1977, 13), "a society of states (or international society) exists when a group of states, conscious of certain common interests and common values, form a society in the sense that they conceive themselves to be bound by a common set of rules in their relations with one another, and share in the working of common institutions." IGOs create new cultures of interaction between states; and "diplomatic culture" for Bull (ibid. 316), are a system of norms and rules that is capable of constraining the behavior of states with diverse ambitions and cultures. Bull and Watson $(1984,9)$ argue that "normative" and "institutional" factors create a unique "logic" for a particular international society (ibid, 9).

This social aspect of potential transformation of conflictual interstate relationships and international norm internalization can be termed socialization. Socialization is a process of inducting actors into the norms and rules of a given community, with compliance based on the internalization of these new norms. The classical, sociological definition of socialization is "the process by which 
actors internalize the expectations of behavior imparted to them by the social environment" (Boekl, Rittberger, and Wagner 1999, 7). Finnemore and Sikkink $(1998,904)$ have pointed out how "state leaders conform to norms in order to avoid the disapproval aroused by norm violation and thus to enhance national esteem (and, as a result, their own self-esteem)." Thus, social norms which can be defined as "intersubjectively shared, value-based expectations of appropriate behavior" may serve as independent variables for explanations of foreign policy behavior (Boekl, Rittberger, and Wagner 1999, 4). Socialization is, therefore, "a process of inducing actors into the norms and rules of a given community" (Alderson 2001; Hooghe 2001). Or, according to the Checkel and Johnston, "the process by which actors acquire different identities, leading to new interests through regular and sustained interactions within broader social contexts and structures" (Checkel 1999, 548; Johnston 2001, 494).

Socialization outcomes equate with the level of target state's compliances, and usually depend on, or result from, the degree to which norms have successfully been inculcated into the target states. There are two major forms of norm internalization. The first aims at norm internalization at the international level, whereas the second form is norm internationalization at the domestic level. Norm internalization at the international level, conducted primarily through the medium of international organizations, often aims at the socialization of state officials and ruling elite groups (top-down socialization). Such socialization may occur among these officials through repeated interactions within international organizations. Domestic level processes take place where the norms are fully internalized or carved into the state's political, social, and legal areas of policy practices. Political internalization occurs with the ruling elite groups' acceptance of norms and, consequently, some degree of change in policies. Social internalization occurs when met with public legitimatization through the wide dissemination of norms into the society. Legal internalization occurs when norms are finally enshrined into the domestic legal measures and practices.

All norm internationalization is enhanced by the socialization process, and perhaps more importantly, the overall adaptations of norms need to be sustained over time. Thereby, states and statesmen, in adopting community rules associated with international organizations and institutions, may switch from following the "logic of consequences to a logic of appropriateness; this adoption is sustained over time and is quite independent from a particular structure of material incentives or sanctions" (Checkel 2005, 804-805). In this paper, particular consideration will be given to the socialization processes in the context of IGOs.

The number and influence of IGOs has increased significantly since the end of the Cold War, and they play crucial roles in diffusing human rights norms and practices. Brian Greenhill (2015) has demonstrated the extent to which IGOs can act as effective human rights norm transmitters. Membership of IGOs 
contributes to changing a target state's human rights norm-violating behavior through international top-down socialization. IGOs become arenas for providing greater opportunities for interactions thereby allowing socialization to occur between member states. In other words, the IGOs generate conditions for socialization to occur through their provision of networks and forums for high-level officials to get together regularly to discuss issues of concern, impacting on a target state's decision-making process (Greenhill 2010). In addition to such a socializing effect the forums also provide opportunities for interpersonal relationships to be fostered (Greenhill 2010). Finally, IGOs and their secretariats can act as direct agents of change, or "norm entrepreneurs," promoting concepts of good governance and acceptable behavior (Finnemore and Sikkink 1998, 893-898). IGOs, therefore, function as both "sites of socialization" and "promoters of socialization" (Checkel 2005, 806-808). Over time the socializing effect leads to internalization, then behavioral and policy change with regard to human rights norms and practices.

There are two prevalent types of socializations currently present in the IGO context. They may be referred to as Type I and Type II socializations (Checkel 2005, 804). Type I socialization is the process through which the norm-violating state learns to respect the rules of the institutions or social contexts within the IGO membership. Type I socialization, simply put, involves the target state in "conscious role playing" in accordance with logic of consequences (Checkel 2005, 804). Essentially, therefore, the socialization process merely serves to impact on the rational decision-making of the target state. Herein, the norm-violating state would make some degree of change in their behavior, but the norms have yet to be internalized sufficiently to change the state's interests (Bearce and Bondanella 2007, 706).

Type II socialization is when target state not only adopts the conscious role-playing behavior, but goes beyond in terms of experiencing a degree of inculcation whereby the logic of appropriateness manifests (Checkel 2005, 804). Thus, the Type II socialization process involves much deeper and larger degrees of socialization effects within the target state. During Type II socialization processes, the target state tends to become much more susceptible to, or adopts new social rules and ideas, regardless of any persuasive incentives provided by other actors. This much deeper level of norm internalization leads, ultimately to the target state experiencing changes in their interests over time (Bearce and Bondanella 2007).

The potential impact of socialization in the IGO context is supported extensively by the wide-ranging transformative impacts on a variety of target states, regardless of their different religious or political foundations. China and Bahrain, for instance, are both undemocratic countries, featuring different religious and political systems, and both of which have exhibited extremely low 
records of overall human rights performances. Reis (2016) have, however, documented a degree of behavioral shift from the Chinese government as a result of socialization in IGO context; in particular through China's increased participation and interaction within the UN Human Rights Council and related UN human rights regimes. Meanwhile, Greenhill's findings indicate that Bahrain's increase in their IGO memberships contributed significantly to the improvements of human rights practices (Greenhill 2015, 82-91). Although the socialization outcomes (the degrees of norm internalizations) for both countries remain somewhere between Type I and Type II socialization processes, the fact that both countries have exhibited some behavioral shifts as a result of socialization processes in the IGO context shows what is possible.

This paper pays particular attention to the process of "acculturation," which is identified in the literature as a socialization mechanism particularly effective for influencing states. Acculturation means "the general process of adopting beliefs and behavioral patterns of the surrounding culture" (Goodman and Jinks 2004, 638; Brown 2000). Behavioral changes are induced through repeated pressures to assimilate and to provide further impetus for compliance within the target state, while the pressures are often imposed by other actors or exogenous mechanisms.

The promotion of human rights norms lies at the center of the UN system of socialization, and indeed even predates the formal establishment of the IGO itself. League of Nations Mandates (followed by UN Trusteeships) established an international principle that states could be held accountable for the human rights of those governed. The Nuremberg trials further established a limit to state sovereignty - states could no longer do as they wished with their citizens, and the UN Charter Preamble reaffirms faith in fundamental human rights without discrimination. This is also reflected in the wording of Articles 1(3), 55 and 56. 1948 saw the landmark Universal Declaration of Human Rights passed by the General Assembly, and this was followed in 1966 by the Covenants on Civil and Political Rights and Economic, Social and Cultural Rights. Meanwhile, the Convention on the Prevention and Punishment of the Crime of Genocide has been ratified by the majority of states, including, in 1989, North Korea (UNTC 2018). For Jack Donnelly (quoted in Dunne and Wheeler 1999, 77) there is a "remarkable international normative consensus on the list of rights" found in the Universal Declaration of Human Rights, and according to Dunne and Wheeler, "[w] hat further strengthens Donnelly's claim that there is a normative consensus underlying the human rights regime is the fact that in the daily round of diplomacy, state leaders justify their human rights policies in terms of these standards" (ibid.)

If anything, since the end of the Cold War, the human rights normative agenda of the UN and its chief norm entrepreneurs has picked up speed. For 
instance, former United Nations Secretary General (UNSG), Boutros Boutros-Ghali noted, "[t]he time of absolute and exclusive sovereignty has passe $\mathrm{d} \cdots$ it is the task of leaders of states today to understand this and to find a balance between the needs of good internal governance and the requirements of an ever more independent world (Boutros-Ghali 1992)." That is to say, as mentioned in the UN Charter, no state is immune to the demands and rights of its internal and external constituencies, and the UN, as the embodiment of the international community will not tolerate the hindrance of its "great objectives" of peace and security, justice and human rights and "social progress and better standards of life in larger freedom." Similar sentiments can be found in the Millennium report penned by Kofi Annan, Boutros-Ghali's successor as UNSG. He also adds that the central task faced by states is to "ensure that globalization becomes a positive force for all the world's people" (Annan, 2000). This Report formed the basis of the Millennium Declaration adopted by Heads of State and Government at the Millennium Summit, held at UN Headquarters in September 2000.

In December 2001 the International Commission on Intervention and State Sovereignty (ICISS) released a report entitled "The Responsibility to Protect" (R2P) which heralded the dawn of a new paradigm in UN governance. At the High-Level Plenary Meeting for the 2005 World Summit (14-16 September) the world's leaders at the General Assembly agreed on a "responsibility to protect" which included a "clear and unambiguous acceptance by all governments of the collective international responsibility to protect populations from genocide, war crimes, ethnic cleansing and crimes against humanity." Resolution 1674 adopted by the United Nations Security Council on April 28, 2006, "Reaffirm[ed] the provisions of paragraphs 138 and 139 of the 2005 World Summit Outcome Document regarding the responsibility to protect populations from genocide, war crimes, ethnic cleansing and crimes against humanity" and commits the Security Council to action to protect civilians in armed conflict. These platforms have received overwhelming and near unanimous support among member countries at the UN, including even Asian countries which, heretofore, had been jealous guardians of state sovereignty and the principle of non-intervention (Howe and Jang 2013, 77).

The Human Rights Council (HRC) of the United Nations, the successor to the Commission on Human Rights (CHR), is the key organ for the pursuit of the human rights agenda at the UN. The evolution of the body itself also holds important lessons for UN socialization. The CHR was initially established in 1946 as a subsidiary of the Economic and Social Council (ECOSOC) (UNSCR 2016, 3). The CHR's major contributions to international socialization of human rights norms include the Universal Declaration of Human Rights and the International Covenants listed above. From the 1970s on, the organization also took the initiative in reviewing human rights violations. The CHR was, however, 
frequently criticized, in particular for not fulfilling its requirements, for the fact that sessions were rarely held, and most problematically, due to a recognition that the CHR was becoming an extremely political and politicized organ which hindered reaching consensus (UNSCR 2016, 3).

As a result, Kofi Annan expressed his deep concerns, identifying a need for major reform of the CHR. He therefore recommended the replacement of CHR with a higher-level body in order to drive forward the human rights agenda. He noted, "[m]y basic premise is that the main intergovernmental body concerned with human rights should have a status, authority and capability commensurate with the importance of its work $\cdots$ so creating a full-fledged council for human rights offers conceptual and architectural clarity (UNSCR 2016, 4)." In March 2006, Resolution 60/251 was adopted by the General Assembly, and the establishment of the new UN human rights organ, the Human Rights Council (HRC), was finally put in force (UNSCR 2016).

The UN has made significant contributions in terms of humanitarian assistance, providing help to nurture the most vulnerable in all areas of the world, and where the help is often urgently needed. In particular, the role that the UN has played in providing humanitarian assistances to the DPRK has been pivotal. Unmet foods, and many other basic needs, are ongoing issues for the majority of the North Korean population, as are the frequent natural disasters such as floods and droughts. Most regions of the DPRK remain extremely disaster prone, while the regime often fails to either respond adequately to disasters when they occur, or to provide immediate assistance for the populations in need. UN agencies were there, however, to provide immediate help and assistance when one of the worst conditions of drought occurred in mid-2017. The United Nations World Food Program (UNWFP) reached 649,431 drought-affected people to provide immediate nutrition support, and the UN Central Emergency Response Fund (CERF) supported 2.5 million dollars for assisting the overall humanitarian project (UNWFP 2017). According to UN data, from 2004 to 2016, about 6.2 million people in total were affected by natural disasters in the DPRK (UNHCT $2018,8)$. The UN and its related agencies have been the only entities consistently providing humanitarian assistance to disaster-affected areas in the DPRK, while the regime restricts aid from other governmental or non-governmental organizations (Haggard and Noland 2007).

In addition to their humanitarian assistance projects in the DPRK, however, the UN has pursued its human rights agendas throughout the organization. One of the most noticeable and influential efforts took place in 2014 (dealt with in more detail in section three). The shocking truths of grave human rights violations committed by the North Korean regime were revealed in detail by the UN Special Commissions' February 2014 report. This, and related reports, received wide attention within and outside of the UN, stimulating 
widespread condemnation and calls for action. Therefore, in late 2014, the UN third committee took the further step, of asking the UNSC to refer the DPRK regime and its authoritarian leader Kim Jong-un to the ICC with a charge of committing "Crimes against Humanity," one of the four specific crimes listed in the R2P legislation. Although this request was unable to pass through the UNSC due to lack of support from China and Russia, it was, nevertheless, supported by the majority UN member countries.

This amounted to "naming and shaming" by UN agencies in order to effect change in the DPRK. This was a far more robust socialization initiative than had been attempted in the past, and not only did it succeed in drawing wider international attention to North Korean human rights violations, but also contributed to bring about changes in the target state as detailed below (Hosaniak 2018; Goedde 2018). Prior to 2014, there had been, in fact, little or no progress made in changing the DPRK's human rights norm-violating behavior. The efforts taken by the UN and rest of the international community were, in many cases, easily overshadowed by the North Korean regimes' non-responsive and non-compliant behaviors. Yet, by 2014, sufficient acculturation had taken place for discernable changes in the pattern of Pyongyang's policy-making to be detected. The social sanction (as opposed to political, economic, or military sanctions advocated by coercive approaches) of human rights naming and shaming had apparently been used successfully by the UN to impose more pressure on the DPRK and its ruling elite groups.

The following section of the paper will, therefore, examine how the UN harnesses acculturation and its processes to socialize recalcitrant states such as the DPRK. It is also important to reiterate, however, that acculturation is process, not an outcome (Chun et al. 2003), and it should be maintained through continuously-repeated interactions rather than a one-time event.

\section{THE EFFICACY OF HUMANITARIAN NORM PROMOTION AND SOCIALIZATION OF THE DPRK}

The DPRK first joined the International Covenant on Civil and Political Rights in 1981; however, obligations were not met. Pyongyang in fact submitted reports to the UN only twice in 1983 and 1987 (Huh 2014, 130). During the Great North Korean Famine in mid-1990s, when the UN expressed the deepest concerns about the situation and Pyongyang's handling of it, the regime responded vehemently and even announced its withdrawal from the Covenant. North Korea's attempted to withdraw from the ICCPR, however, failed because there was no consent of the other parties. During the early 2000s, European nations wrote several letters of concern about the human rights situation in North Korea, requesting further dialogue. The DPRK did not, however, respond to any 
of those requests or letters (Huh 2014, 131). Therefore, in 2003, the first North Korean Human Rights Resolution was adopted by the UNCHR. Along with the Resolution, Bertrand Ramcharan, who was Acting High Commissioner at that time, sent a document to the DPRK requesting further cooperation on human rights concerns (E/CN.4/2004/31 2004). Again, however, there was no response.

The UN was becoming increasingly concerned about the overall human rights situation in the DPRK. The issue was brought up, therefore, in the UN's Committee on Economic, Social and Cultural Rights (CESCR), where a wide-ranging report on the human rights situation in the DPRK was discussed. The DPRK's response was, however, once again, extremely uncooperative, and the country's representatives were unwilling to answer during the questioning session. The international community even felt that they were "talking to a wall" when trying to have dialogue with DPRK representatives (E/CN.4/2004/31 2004). In late 2003, Ramcharan once again sent a letter to the DPRK, this time requesting more cooperation with the UN's activities for improving human rights conditions in the DPRK (Huh 2014, 133-134). The DPRK surprisingly responded to Ramcharan's request and said "the DPR Korean government considers closer cooperation sincerely," but no substantial actions followed from Pyongyang. They further resisted responding to any of the UN investigational team's requests to visit Pyongyang other than allowing a single visit by the Chairman of the Human Rights Committee and one UN personnel to visit the country during April 2004 (Huh 2014, 133-134).

Because of the DPRK's non-responsive and non-compliant behavior, the UNCHR pushed for a third North Korean Human Rights Resolution, which ultimately was adopted by the UN General Assembly in late 2005 (A/RES/60/173 2005). The Resolution recognized wide-ranging human rights violations in the DPRK, also expressed concerns regarding non-compliant behavior by the DPRK, and therefore strongly urged "the General Assembly to take up the question of the situation of human rights in the Democratic People's Republic of Korea if the government did not extend cooperation to the Special Rapporteur of the Commission on the situation of the human rights in the Democratic People's Republic of Korea and if no improvement of the situation of human rights in the country was observed...”(A/RES/60/173 2005, 1). The Resolution also noted that the DPRK intended to resist any further humanitarian assistance by the UN or other instruments of the international community, which would inevitably lead to further degradation of human rights in North Korea (A/RES/60/173 2005, 2).

The DPRK's non-responsive and non-compliant behaviors remained unchanged. For instance, in 2011, the UNGA adopted another North Korean Human Rights Resolution (A/RES/66/174) which expressed deep concern about the DPRK regime's non-compliant and human rights norm-violating behavior. By this time the regime had also halted family reunion events (of families separated 
by the Korean War, who found themselves on opposite sides of the de-militarized zone, the de facto border between North and South Korea after the armistice) and inter-Korean dialogues. More problematically, there were ongoing and persistent food insecurity problems within the country. The regime was unable to resolve the situation while refusing to abide by international human rights norms and practices (A/RES/66/174 2011).

Things came to a head with the February 2014 report of the UN special committee, and the requested referral of Kim Jong-un to the ICC on a charge of crimes against humanity. This can, however, be considered a turning point, as the naming and shaming involved in this procedure represented a considerable escalation of socialization pressure by the $\mathrm{UN}$, and ultimately it had a substantial impact on the regime.

Franklin $(2015,44)$ has noted that this approach amounts to "[t]he collection and dissemination of evidence of human rights violations, with the goal of embarrassing, or shaming, governments into complying * shaming refers to the strategic purpose behind, naming *will convince the target to desist such widely condemned actions." Likewise, for Bull $(2002,54)$ social sanctions such as naming and shaming the norm-violating state can affect them by publicly exposing their violating actions thereby inducing behavioral changes. Human rights naming and shaming method appears to be more effective when it is used by human rights organizations (Murdie and Davis 2012). Ann Marie Clark (2013) further finds that the naming and shaming method has often been effective when utilized by international organizations such as the UN Human Rights Commission (UNHRC). The naming and shaming practiced by the UNHRC in 2014 represents one such effective case as it finally managed to generate some level of substantial behavioral change by the DPRK.

The DPRK's neglect of the fundamental rights of human beings is perhaps deeply rooted in the political culture of the country. The Juche system, which is the basis for all political, social, and economic frameworks in the DPRK, only considers the public at large rather than each individual, focusing on national political, economic, and military self-reliance. Therefore, what are considered internationally as fundamental human rights have, in many cases, been completely ignored in the DPRK (Kim 1997, 42-43). Essentially, all aspects of the universal human rights paradigm go unrecognized in North Korea (KINU 2001, 12-15). Pyongyang has always claimed to respect its own version of human rights based on Juche. The logic of the DPRK's argument, simply put, is that the system they have is different from those of other nations, therefore, their human rights problems should not be judged against the international norms and standards. Moreover, the DPRK has always argued that human rights considerations are a matter of state sovereignty, which should not be interfered with by the UN or international community (Kim 2007, 337-338). They further claim that they do 
not have any human rights problems (Lee 2010, 29-30). Pyongyang, therefore, is selective in its responses to UN requests and recommendations (Min 2014, 120).

In the 2014 proceedings, however, Kim Jong-un's name was, for the first time, mentioned in the shaming process in an international arena. The DPRK's initial reactions were, not surprisingly, very hostile. The DPRK first completely denied all the accusations of human rights violations identified in the special commission of enquiry report, further claimed that the report was totally distorted, and also that it was not credible since it was compiled by the UN, and finally that it was the result of political manipulation by the United States (KINU 2015, 39). Yet, relatively soon after this very public naming and shaming, it was possible to detect a shift in Pyongyang's positioning.

From July to September 2014, much of the hostility from the DPRK remained, but the DPRK began to respond to UN requests. Reconciliatory gestures included the release of American detainees, an announcement at the UN headquarters in New York in October 2014 stating a willingness to engage in more human rights talks with concerned international partners, and an invitation to the EU special representatives and the UN special Rapporteur to visit the DPRK. Furthermore, during the $69^{\text {th }}$ session of the UN General Assembly, the DPRK's Foreign Minister, Ri Su-Yong, expressed willingness to enlarge cooperation on human rights issues with the UN and international community. $\mathrm{He}$ announced that the DPRK was "willing to facilitate technical cooperation, contacts, and communication with the UN and other international human rights organizations" (KINU 2015, 45). Although modest, by comparison with previous stonewalling, these developments signaled major positional shifts in Pyongyang. The Korea Institute for National Unification (KINU), a South Korean think tank, called the DPRK's behavioral modification, "the most drastic change in the DPRK's position" (KINU 2015, 42). Actual implementation conditions had yet to be met, however.

Because the DPRK was still not in full compliance, the UN Third Committee took further action and the COI report was brought up to the UNGA on October 18, 2014. Once again, the DPRK claimed that it was a political conspiracy by the US and the ROK (KCNA 2014). The DPRK also threatened nuclear war with the ROK, and hosted state-led rallies against the Human Rights Resolution in Pyongyang in November 2014 (KINU 2015, 51). Nonetheless, the Human Rights Resolution was adopted by the UNGA on December 18, 2014, and the UN applied further pressures to the DPRK regime by requesting the UNSC refer Kim Jong-un to the ICC for crimes against humanity. This explicit and public naming and shaming of Kim Jong-un eventually became the gateway to induce behavioral changes by the DPRK (KINU 2015). The Kim Jong-un regime and its ruling elites felt embarrassment (KINU 2015). Also, of great significance, was the understanding that the dignity and legitimacy of the supreme leader had 
been hurt, challenged, and denied (KINU 2015, 54).

Following the socialization processes of 2014, there were significant policy shifts in Pyongyang. In particular, there were major developments around increased engagement with the international human rights regime and related NGOs with regard to persons with disabilities. For instance, the DPRK agreed upon to build the Daedonggang recovery center for disabled people, and provide medical support, education for recovery, sports and cultural programs for disabled in cooperation with a South Korean non-governmental organization, Green Tree Korea (greentreekorea.org; KINU 2015). The DPRK invited 18 deaf students from Japan, Singapore, and Netherlands to the country during August 2014. On November 2014, the regime-led group of disabled citizens made a visit to Finland and held a meeting with Sirpa Paatero, the Finnish minister of foreign trade and development (KINU 2015). In 2014, the DPRK also allowed disabled athletes to participate in international sporting events such as Incheon Asian Games (Kim 2014), and a goodwill soccer match in Australia (Lee 2014). The regime promoted a small musical ensemble of disabled students (Lee 2015), which performed in the UK in 2015 (BBC 2015).

On December 6, 2016; the DPRK finally ratified the Convention on the Rights of Persons with Disabilities (UNHRC 2017, 3), as well as the Marrakesh Treaty to Facilitate Access to Published Works for Persons Who Are Blind, Visually Impaired or Otherwise Print Disabled (UNGA 2017, 5). Along with the ratification of the international treaties for the disabled, domestically the DPRK established Specific Protection Targets for Disabled, and much more positive attitudes by the regime towards the disabled groups were observed (KINU 2015). Also, notably, during much of this period, the DPRK regime refrained from directly criticizing the UN (KINU 2015, 40).

In May 2017, during her first ever visit to the DPRK, Catalina Devandas Aguilar, the UN Special Rapporteur on the rights of persons with disabilities, was be able to observe significant progress. In 2016, in line with article 33(1) of the Convention, the DPRK had established the Central Committee for the Protection of Persons with Disabilities within the Cabinet, as well as the Korean Federation for the Protection of the Disabled in 2016. The Federation office in Pyongyang hired 20 full time staff and 4 persons with disabilities. To enhance their agenda, the regime planned on establishing provincial branches of the Federation, with additional staff to assist persons with disabilities and was in the process of developing a strategic national action plan for the protection of disabled people (UNGA 2017, 6-7). In 2014, with limited preexisting data, the DPRK regime had conducted a disability sample survey in four provinces; South Hamgyong, Kangwon, North/South Pyongan in cooperation with the United Nations Population Fund (UNFPA). In 2017, the Ministry of State Construction Control indicated that persons with disabilities who reside in Pyongyang could use taxi 
services for free (UNGA 2017, 10). The DPRK regime also expected a new rehabilitation center for disabled people to be built in Pyongyang by the end of 2018 (UNGA 2017, 14).

The DPRK has further moved to focus on the human rights of women and children. While the 2014 pressures were still being applied, the DPRK finally ratified the Optional Protocol to the Convention on the Rights of the Child (CEDAW/C/PRK/CO/2-4 2017). The regime submitted periodic reports to the Committee on the Rights of Child and the Committee on the Elimination of Discrimination against Women in 2017 for the UN to consider (UNHRC 2017; $\mathrm{CEDAW} / \mathrm{C} / \mathrm{PRK} / \mathrm{CO} / 2-4$ 2017).

This is not to claim that as a result of the naming and shaming socialization process the DPRK is now fully compliant with the international human rights regime. The DPRK has yet to ratify other core international human rights treaties such as, 1) The Convention against Torture and Other Cruel, Inhuman or Degrading Treatment or Punishment; 2)The International Convention for the Protection of All Persons from Enforced Disappearance; 3) The International Convention on the Elimination of All Forms of Racial Discrimination; 4) The International Convention on the Protection of the Rights of All Migrant Workers and Members of Their Families (CRC/C/PRK/CO/5 2017). What this does reveal, however, is that although it may take a while, through socialization processes at the UN, there is great potential that the DPRK will be willing to make commitments to these remaining treaties

On the ground in the DPRK, actual human rights conditions remain dire. The latest report of the United Nations' Special Rapporteur on the situation of human rights in the DPRK identified that the DPRK regime has violated economic, social and cultural rights, and civil and political rights of their citizens (UNHRC 2018). The condition of many prisoners in detention camps in the DPRK remains a critical issue, as does the plight of foreign national (including South Korean) detainees (OHCHR 2017; BBC 2018). The inhumane treatment of inmates includes denial of basic human needs such as clean drinking water and sanitation (UNHRC 2018). Inmates have often been physically and mentally tortured and abused, with minimal rights such as the right to a fair trial not guaranteed (UNHRC 2018). Freedom of thought and access to information still is significantly restricted. Furthermore, food insecurity is an ongoing chronic problem in the DPRK. Approximately 10.3 million people, or 41 percent of the population are food insecure (UNHCT 2018).

Adequate conditions to protect refugees have not been met. Kim Jong-un has not only further tightened border security since taking power, but has also ordered guards to "shoot to kill" those attempting to cross borders (CRHRP 2017, 15-16). He ordered 340 public executions from 2012 to 2016, including more than 140 government officials (INSS 2016). Corruption and the abuse of power 
and authority by officials are widespread, negatively impacting upon many ordinary citizens (CRHRP 2017, 17-18). The regime has refused to recognize or guarantee minimal rights for all workers. There are no labor organizations formed by the workers, only a few state-led organizations organized and completely controlled by the regime. The regime controls all aspects of employment, assigning jobs and determining wages for all workers in the DPRK (CRHRP 2017, 23). Mobilizations of forced labor garner the regime about 975 million dollars each year (CRHRP 2017, 23-24). Despite the policy changes listed above, discrimination against the disabled remains widespread in North Korean society, especially outside of Pyongyang (UNHRC 2018).

The regime's nuclear prioritization has been extremely problematic, not only because of the threat it poses to international security, but also because it diverts resources from humanitarian operations, provokes ongoing sanctions by the international community, and could even become a humanitarian crisis in North Korea. The UN Special Rapporteur has expressed concern that radioactive fallout may contaminate the environment and impact citizens' health (UNHRC 2018 , 11). Furthermore, the fact that the nuclear issue has become the number one concern for the majority of international actors, the human rights situation of the DPRK has usually been put aside. Treating human rights issues as equally important as nuclear issues is crucial. Tomas Quintana, the UN special rapporteur on human rights in the DPRK noted by his statement in April, "A denuclearization deal will remain fragile if it sidelines rights and needs of the DPRK population" (CRS 2018).

\section{CONCLUISION}

North Korea clearly remains a grave violator of human rights. Attempts to coerce or incentivize the DPRK to change its ways have, on the whole, failed, and worse, may even be counter-productive. This paper has, however, demonstrated at least a modicum of hope for the efficacy of socialization measures at the $\mathrm{UN}$ in promoting change in Pyongyang. While the naming and shaming mechanism in 2014 appears to have had the greatest effect, this impact was only felt in Pyongyang because of the degree of socialization through engagement with the international community, which had already taken place. It is within the wider socializing normative framework of the United Nations that further progress on safeguarding human rights in North Korea needs to be sought.

In 2016, the UN and the DPRK jointly agreed upon "The Strategic Framework 2017-2021," which was designated as the medium and framework for considering all areas currently of concern regarding human rights in North Korea and areas for improvement. The strategic framework represents not only an opportunity directly to promote human rights in the DPRK, but also to enhance 
socializing effects among ruling elites and the people of the country through increased engagements. The UN must, therefore, continue to play a central role in sustaining mechanisms for initiating change and encouraging the DPRK to abide by international human rights norms by advocating a policy of engagement with, rather than isolation of the DPRK.

That being said, the majority of UN engagement with the DPRK aimed at transforming policy prioritization in Pyongyang, including the much-vaunted naming and shaming, really only addresses Type I socialization whereby the norm-violating state learns to respect the rules of the institutions or social contexts within the IGO membership. In order to construct a truly stable and self-perpetuating human rights compliant regime in North Korea, wherein the target state adopts new social rules and ideas, regardless of any external incentives, the UN needs to explore mechanisms for moving towards Type II socialization. Given the political culture of the DPRK and the nature of social relations, this will require much greater and deeper socialization efforts in order to promote a "norm cascade" in the country.

Karl Deutsch $(1978,119-122)$ refers to a simple cascade model of national decision-making consisting of five levels, each level a distinct reservoir of public or elite opinion and each reservoir linked to a complex of social institutions and status groups. The first of these is the social and economic elite, which does not form a simple monolithic group, but rather is connected by a dense net of multiple ties, links, and channels of communication. The second is the political and governmental elite, which is also not monolithic. Third we have the media of mass communication, fourth the network of local opinion leaders, and fifth the politically relevant strata of the population at large. Streams of information move downward in cascade fashion, from higher-level communications systems to lower-level ones. Likewise, for Risse, Ropp and Sikkink, policy prioritization in a target state can socially constructed through the socialization of the states, or their elites, or through a norm "cascade" or "spiral" model, whereby human rights norms permeate down through conflictual levels of society.

In order for UN socialization processes to remain relevant, and to increase their efficacy, all channels of communication with Pyongyang must remain open, and new channels constructed between the international community and different tiers of North Korean society.

\section{REFERENCES}

Alderson, Kai. 2001. "Making Sense of State Socialization." Review of International Studies 27(3): 415-433.

Annan, Kofi. 2000. "We the Peoples: The Role of the United Nations in the 21st 
Century Presented to the General Assembly by Secretary-General on 3 April 2000." Accessed August 8, 2018. http://www.un.org/en/events/ pastevents/pdfs/We_The_Peoples.pdf.

BBC. 2015. "Oxford Concert is a First for Disabled North Korea Performers."

BBC. February 20, 2015. https://www.bbc.com/news/av/uk-31558421/oxfordconcert-is-a-first-for-disabled-north-korea-performers.

BBC. 2018. "North Korea Frees Three US Detainees Ahead of Trump Summit." $B B C$. May 9, 2018. https://www.bbc.com/news/world-us-canada-44056972.

Bearce, David H. and Stacy Bondanella. 2007. "Intergovernmental Organizations,

Socialization, and Member-State Interest Convergence." International Organization 61(4): 703-733.

Boekl, Henning, Volker Rittberger and Wolfgang Wagner, W. 1999. Norms and Foreign Policy: Constructivist Foreign Policy Analysis. Tubingen: University of Tubingen Press.

Boutros-Ghali, Boutros. 1992. "An Agenda for Peace: Preventive Diplomacy, Peacemaking and Peace-keeping." New York: United Nations.

Brown, Rupert. 2000. Group Processes: Dynamics Within and Between Groups. New Jersey: Wiley-Blackwell Publisher.

Bull, Hedley. 1977. The Anarchical Society: A Study of Order in World Politics. London: Macmillan.

Bull, Hedley. 2002. The Anarchical Society: A Study of Order in World Politics, $4^{\text {th }}$ Ed. New York: Columbia University Press.

Bull, Hedley and Adam Watson. 1984. The Expansion of International Society. Oxford: Oxford University Press.

Baek, Bum Seok. 2013. "Understanding and Future Prospects of the UN COI on North Korean Human Rights Situation." Seoul: Korea Institute for National Unification (KINU).

Biersteker, Thomas. 2015. "UN Targeted Sanctions as Signals: Naming and Shaming or Naming and Stigmatizing?" Pp. 165-184 in The Politics of Leverage in International Relations: Name, Shame, and Sanction, edited by H.R. Friman. Basingstoke: Palgrave Macmillan.

Cardenas, Sonia. 2009. "Human Rights in Comparative Politics." In Human Rights: Politics \&Practice, edited by M. Goodhart. Oxford: Oxford University Press.

Checkel, Jeffrey T. 1999. "Social Construction and Integration." Journal of European Public Policy 6(4): 545-560.

Checkel, Jeffrey T. 2005. "International Institutions and Socialization in Europe: Introduction and Framework." International Organization 59(4): 801-826.

Clark, Ann Marie. 2013. "The Normative Context of Human Rights Criticism: Treaty Ratification and UN Mechanisms." Pp. 125-144 in The Persistent Power of Human Rights: From Commitment to Compliance, edited by T. 
Risse, S. C. Ropp and K. Sikkink. Cambridge and New York: Cambridge University Press.

Chun, Kevin M., Pamela B. Organista, Gerardo Marin and Stanley Sue. 2003. Acculturation: Advances in Theory, Measurement, and Applied Research. Washington, D.C.: American Psychological Association.

Deutsch, Karl. 1978. The Analysis of International Relations, second edition. New Jersey: Prentice-Hall.

Finnemore, Martha and Kathryn Sikkink. 1998. "International Norm Dynamics and Political Change" International Organization 52 (4) 887 - 917.

Franklin, James C. 2015. "Human Rights Naming and Shaming: International and Domestic Processes." In The Politics of Leverage in International Relations: Name, Shame, and Sanction, edited by H. Friman. USA: Palgrave Macmillan. Goedde, Patricia. 2018. "Human Rights Diffusion in North Korea: The Impact of Transnational Legal Mobilization.” Pp. 154-176 in North Korean Human Rights, edited by A. Yeo and D. Chubb. Cambridge and New York: Cambridge University Press.

Goodman, Ryan and Derek Jinks. 2004. "How to Influence States: Socialization and International Human Rights Law." Duke Law Journal 54(3): 621-703.

Greenhill, Brian. 2010. "The Company You Keep: International Socialization and the Diffusion of Human Rights Norms." International Studies Quarterly 54(1): 127-145.

Greenhill, Brian. 2015. Transmitting Rights: International Organizations and the Diffusion of Human Rights Practices. New York: Oxford University Press. Haggard, Stephen and Marcus Noland. 2007. Famine in North Korea: Markets, Aid and Reform. New York: Columbia University Press.

Hooghe, Liesbet. 2001. The European Commission and the Integration of Europe: Images of Governance. Cambridge: Cambridge University Press.

Hosaniak, Joanna. 2018. "NGOs As Discursive Catalysts at the United Nations and Beyond: An Activist's Perspective." Pp. 131-153 in North Korean Human Rights, edited by A. Yeo and D. Chubb. Cambridge and New York: Cambridge University Press.

Howe, Brendan. 2012. "Beyond Security Towards Peace on the Korean Peninsula: Strategies for Transforming a Nuclear Conflict." Korean Journal of Security Affairs 17 (1) 65-82.

Howe, Brendan M. and Suyoun Jang. 2013. "Promoting Human Security through the United Nations: UN Contributions and Policy Implications." The Korean Journal of Security Affairs 18(1): 62-82.

Howe, Brendan M. and Jason Park. 2014. "Addressing North Korean Security Challenge through Non-State-Centric International Economic Engagement." North Korean Review 10 (1) 39-54.

Huh, Man Ho. 2014. The Human Rights Situations in North Korea. Daegu: 
Kyongbuk National University Press.

Institute for National Security Strategy (INSS). 2016. "White Paper on Five Years of Kim Jong-Un Rule.” Seoul: INSS.

Johnston, Alastair Iain. 2001. "Treating International Institutions as Social Environments." International Studies Quarterly 45(4): 487-515.

Johnson, David E., Karl P. Mueller and William H. Taft. 2002. "Coercion across the Spectrum of Operations: The Utility of U.S. Military Forces in the Emerging Security Environment." Santa Monica, CA: Rand.

Karns, Margaret P., Karen A. Mingst and Kendall W. Stiles. 2015. International Organizations: The Politics and Processes of Global Governance. 3rd ed. Boulder: Lynne Rienner Publisher.

Kim, Ji Hyun. 2014. "North Korea sent Athletes with Disabilities to Asian Games in Incheon." Yonhap News. September 3, 2014. https://news.naver.com/ main/read.nhn?mode=LSD\&mid=sec\&sid $1=102 \&$ oid $=001 \&$ aid $=0007103$ 443.

Kim, Soo Am. 2007. "North Korea's Response on Questions Raised by the International Society." Seoul: National Human Rights Commission of the Republic of Korea.

Kim, Soo Am, Dong Ho Han, Kyong Ok Do, Keum Soon Lee and Min Hong.

2015. "White Paper on Human Rights in North Korea." Seoul: Korea Institute for National Unification (KINU).

Kim, Uk Rak. 1997. "Understanding Human Rights from Juche Perspective." 43(4). Pyongyang: Kim Il Sung University Press.

KINU Center for North Korean Human Rights Studies. 2015. "Implementation Strategies for Policies on North Korean Human Rights." Study Series 15-04. Seoul: Korea Institute for National Unification.

Lee, Gwang Hyuck. 2010. "The Falsification of Imperialists' Human Rights Advocacy." Politics and Law Research 13(31). Pyongyang: Encyclopedia of Science Press.

Lee, Joo Seung. 2015. "The Overseas Performances of North Korean Music Band for Disabled, North Korea's Tit-for-Tat Actions to the International Community?" MBC News, February 21, 2015.

http://imnews.imbc.com/replay/2015/nwdesk/article/3655163_17821.html.

Lee, Young Jae. 2014. "North Korean Athletes with Disabilities will participate in Goodwill Soccer Game in Australia." Yonhap News. December 3, 2014. http://www.yonhapnews.co.kr/bulletin/2014/12/03/020000000 0AKR20141203046700014.HTML?input $=1195 \mathrm{~m}$.

McCurry, Justin. 2016. "Seoul Shuts Down Joint North-South Korea Industrial Complex." The Guardian, February 10, 2016. https://www.theguardian.com/ world/2016/feb/10/seoul-shuts-down-joint-north-south-korea-industrial-co mplex-kaesong. 
Min, Kyung Bae. 2014. "The Viewpoints and Responses of North Korea towards UN Human Rights Law.” Inha Law Review, 17(1): 109-138.

Murdie, Amanda M. and David R. Davis. 2012. "Shaming and Blaming: Using Events Data to Assess the Impact of Human Rights INGOs." International Studies Quarterly 56(1): 1-16.

Nincic, Miroslav. 2006. "The Logic of Positive Engagement: Dealing with the Renegade Regimes." International Studies Perspectives 7(4): 321-341.

Office of the High Commissioner for Human Rights (OHCHR). 2014. "Report of the Detailed Findings of the Commission of Inquiry on Human Rights in the Democratic People's Republic of Korea (A/HRC/25/CRP.1)." New York: United Nations

Office of the High Commissioner for Human Rights (OHCHR). 2017. "US Student Case is Reminder of Prison Conditions in North Korea-UN Rights Expert." OHCHR. June 16, 2017. https://www.ohchr.org/EN/NewsEvents/ Pages/DisplayNews.aspx?NewsID=21761\&LangID=E.

Noland, Marcus. 2008. "The (non) Impact of UN Sanctions on North Korea." Peterson Institute for International Economics, Working Paper Series.

Reis, Isis Sartori. 2016. "China and the United Nations Human Rights Council: Understanding Processes of Socialization and Norm Shaping." Master's Thesis., Lund University.

Risse, Thomas, Stephen C. Ropp and Kathryn Sikkink. 1999. The Power of Human Rights: International Norms and Domestic Change. Cambridge: Cambridge University Press.

United Nations Committee on the Elimination of Discrimination against Women.

2017. "Convention on the Elimination of All Forms of Discrimination against Women." CEDAW/C/PRK/CO/2-4, November 22.

United Nations Committee on the Rights of the Child. 2017. "Convention on the Rights of the Child: Concluding Observations on the Fifth Periodic Report of the Democratic People's Republic of Korea." CRC/C/PRK/CO/5, October 23.

United Nations Economic and Social Council. 2004. "Question of the Violation of Human Rights and Fundamental Freedoms in Any Part of the World: Situation of Human Rights in the Democratic People's Republic of Korea, Note by the Secretariat." E/CN.4/2004/31, February 17.

United Nations General Assembly. 2005. Resolution 60/173, A/RES/60/173, December 16, 2005.

United Nations General Assembly. 2012. Resolution 66/174, A/RES/66/174, March 29, 2012.

United Nations General Assembly. 2018. Resolution 72/188, A/RES/72/188, January 19, 2018.

The Humanitarian work of the UN Country Team (UNHCT). 2015. "DPR Korea 
2015: Humanitarian Needs and Priorities.” New York: United Nations. The Humanitarian work of the UN Country Team (UNHCT). 2016. "DPR Korea 2016: Humanitarian Needs and Priorities.” New York: United Nations.

The Humanitarian work of the UN Country Team (UNHCT). 2017. "DPR Korea 2017: Humanitarian Needs and Priorities.” New York: United Nations.

The Humanitarian work of the UN Country Team (UNHCT). 2018. "DPR Korea 2018: Humanitarian Needs and Priorities.” New York: United Nations.

United Nations Human Rights Council (UNHRC). 2017. "Report of the Special Rapporteur on the Situation of Human Rights in the Democratic People's Republic of Korea." A/HRC/34/66, February 22.

United Nations Human Rights Council (UNHRC). 2017. "Report of the Special

Rapporteur on the Rights of Persons with Disabilities on Her Visit to the Democratic People's Republic of Korea, Note by the Secretariat." A/HRC/37/56/Add.1, December 8.

United Nations Human Rights Council (UNHRC). 2018. "Report of the Special Rapporteur on the Situation of Human Rights in the Democratic People's Republic of Korea, Note by the Secretariat." A/HRC/37/69, March 9.

United Nations Security Council. 2006. Resolution 1695, S/RES/1695, January $15,2006$.

United Nations Security Council Report. 2016. "Human Rights and the Security Council- An Evolving Role.” Research Report. New York: United Nations.

United Nations Security Council Report. 2018. "Monthly Forecast." May 2018. New York: United Nations.

United Nations Security Council Report. 2018. "Monthly Forecast." August 2018. New York: United Nations.

United Nations Treaty Collection (UNTC). 2018. "Treaty Series, Vol. 78." New York: United Nations. https://treaties.un.org/doc/Publication/MTDSG/Volume $\%$ 20I/Chapter\%20IV/IV-1.en.pdf.

United Nations World Food Programme (UNWFP). 2017. "WFP DPR Korea Country Brief." August 31, 2017.

United States Department of State. 2017. "Country Report on Human Rights Practices for 2017: Democratic People’s Republic of Korea 2017 Human Rights Report." Washington, DC: Bureau of Democracy, Human Rights and Labor.

Yun, Sarah. 2009. "Kaesong Industrial Complex: Is it Changing the DPRK?" SAIS U.S.-Korea Yearbook 2009. Johns Hopkins University: U.S.-Korea Institute at SAIS. 